\title{
Digital Fuzzy Current Controlled Light-Emitting Diode Driver with Power Factor Correction
}

\author{
A. S. Veerendra $\left(\mathbb{D},,^{1,2}\right.$ A. A. Shah $\mathbb{D}^{1},{ }^{1}$ M. SubbaRao $\triangle{ }^{3},{ }^{3}$ and M. R. Mohamed $\mathbb{D}^{2}$ \\ ${ }^{1}$ Key Laboratory of Low-Grade Energy Utilization Technologies and Systems, MOE, Chongqing University, Chongqing 400030, China \\ ${ }^{2}$ College of Engineering, Universiti Malaysia Pahang, Gambang, 26300 Kuantan, Pahang, Malaysia \\ ${ }^{3}$ Department of Electrical and Electronics Engineering, Vignan's Foundation for Science, Technology and Research, Vadlamudi, \\ Andhra Pradesh, India
}

Correspondence should be addressed to A. A. Shah; akeelshah@cqu.edu.cn and M. R. Mohamed; rusllim@ump.edu.my

Received 17 December 2020; Revised 1 February 2021; Accepted 4 March 2021; Published 15 March 2021

Academic Editor: Francesco Riganti Fulginei

Copyright ( 2021 A. S. Veerendra et al. This is an open access article distributed under the Creative Commons Attribution License, which permits unrestricted use, distribution, and reproduction in any medium, provided the original work is properly cited.

This paper presents the design and development of a fuzzy peak current controlled (FPCC) single-stage single-phase nonisolated AC/DC high-power factor LED drive. The proposed controller includes a fuzzy logic controller (FLC) in the loop voltage and a peak current controller in the loop current for an integrated nonisolated LED driver to attain a high-power factor (PF). The proposed control avoids complexities related to nonlinearities of the converter. The control action is initially derived from a group of rules written in accordance with experience and intuitive reasoning. The proposed technique is realized using a DSP processor (TI-TMS320F2812), which is capable of executing a high number of instructions in one cycle. A $70 \mathrm{~W}, 350 \mathrm{~mA}$ LED driver operating with an input of $90 \mathrm{~V}-230 \mathrm{~V}, 50 \mathrm{~Hz}$ was designed and implemented using MATLAB/Simulink. The results of the driver are in accordance with international regulations. The steady-state and transient responses are validated experimentally.

\section{Introduction}

An LED is a semiconductor unit that emits visible light when a current is passed through it. Lamps have good efficiency, are mercury free, and are long lasting $[1,2]$. An LED provides control over light distribution with lenses or small reflectors and affords adaptability in the design of lighting apparatuses [3]. A block diagram of driver circuit is shown in Figure 1. In the case of a sinusoidal supply voltage, the driver must draw a sinusoidal current from the mains. To achieve this, an active filter is used along with a switched-mode power supply in one of two designs, namely, two-stage [4-7] and single-stage [812] power factor correction (PFC) topologies.

The two-stage power factor correction approach utilizes an input current shaping converter ahead of the DC/DC converter. Both of the converters are controlled individually to accomplish PFC and fast voltage regulation. This technique is known for its superior performance, such as high-power factor and low input current harmonics, which is achieved at the cost of additional circuitry (including control circuitry). This might not be justified for low-power applications. Subsequently, a one-stage design was proposed by using the concept of integration $[13,14]$. In [15], an integrated buck-boost driver with classical controllers is examined for LED applications. It consists of a single control switch operated in buck and boost modes. The main drawback of the topology is a high value of storage capacitance and a voltage ripple. To minimize the capacitance, Soares et al. discussed a slope compensation technique in [16]. However, the ripple content is still increased in the voltage and current responses.

A driver may suffer damage if the current is higher than the rated current. In order to restrict the current, a closedloop system control is important. Severe working conditions in terms of temperature and current density certainly influence the efficiency of LEDs [17]. The LED is used not only for lighting but also for several other applications such as computer or scoreboard displays. For such applications, the LED needs a driver that can control the voltage for all of the lamps. A fast settling time is also necessary for a scoreboard, due to high lighting motion from one LED to another 


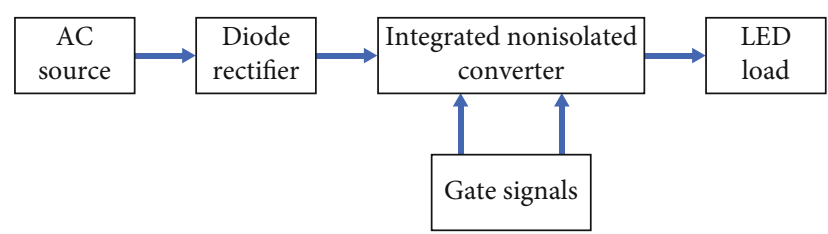

Figure 1: Block diagram of the driver.

within 5 to $100 \mathrm{~ms}$. The color changing requires rapid responses in the current value and a stable voltage; therefore, proper control of the current and voltage distributions is required.

In recent years, there has been an increasing interest in control strategies to enhance the dynamic behavior of AC/DC converters. Classical (PI, sliding mode) and intelligent (fuzzy, neurofuzzy) control techniques are used in the literature to improve the performance of drivers. In [1821 ], the authors considered converters possessing linear characteristics, but this strategy is not appropriate for some operating conditions. Moreover, there exists uncertainty due to source variations and load changes. Fuzzy logic control (FLC) is advantageous in this regard because it can accommodate parameter variations in the system and can therefore incorporate modeling uncertainty, neglected components, and nonlinearities [22-24]. Knowledge-based FLC attempts to code human knowledge, experience, and acumen to be able to make informed choices about the performance of the system. Knowledge-based FLC is a fuzzy rule base with suitable choices to control the activity of the plant under examination without human intervention [25-29]. In [30], the authors were able to achieve a PF of 0.98 and 13\% THD using a digital fuzzy controller.

All passive components constituting the converters can be described by linear characteristics. This assumption is obviously not valid under all operational conditions, particularly since the inductance coefficients vary with the current. Moreover, there exists modeling uncertainty in the presence of input voltage fluctuations, load changes, and values of the component coefficients. Hence, in this work, we propose and develop a FLC in-the-loop voltage and fixed frequency peak current controller in the loop current for an integrated nonisolated LED driver. Unlike conventional controllers, a fuzzy peak current controller (FPCC) is used. To maintain performance under coil magnetic saturation and model uncertainty, FLC is selected because it can deal with the aforementioned uncertainty and variations, as well as neglected elements and nonlinearities. In this work, we consider source variations and load changes. The proposed controller attains a high-power factor (PF) with a low \%THD, comparing favourably with conventional methods. Furthermore, the voltage loop driver feeds a regulated voltage to the LED panel. The DSP is a better option to realize the proposed FPCC due to its fast execution. Moreover, the driver is low cost, so that the controller and processor are affordable.

The objectives of this work are as follows:

(1) To design and develop an intelligent controller that can act effectively during source variations and load changes
(2) To achieve a high-power factor with a driver circuit during source and load variations in order to comply with international standards

(3) To attain a low \%THD for any source and load variations in order to comply with international standards

\section{Analysis of LED Driver}

The integrated nonisolated LED driver is depicted in Figure 2, and the corresponding parameters are explained as follows.

2.1. Mains Current and Power. The current through $L_{1}$ during $\left(0-D T_{S}\right)$ is the line current $\left(i_{s}\right)$, where $D$ is duty cycle and $T_{s}$ is switching time period. The value of the mains current averaged at line frequency can be obtained using

$$
\left(i_{s}\right)=\frac{1}{T_{s}} \frac{1}{2} i_{s_{\text {peak }}} D T_{s}=\frac{D^{2} V_{s}}{2 L_{1} f_{s}} \sin \left(w_{L} t\right),
$$

where $i_{s_{\text {peak }}}$ is the instantaneous peak current, $f_{s}$ is the switching frequency, and $V_{s}$ is the peak line voltage. From Equation (1), the line current is sinusoidal in shape, and subsequently, the power factor $(\mathrm{PF})$ is unity by filtering electromagnetic interference $(\mathrm{EMI})$ with a filter. The mean input power $\left(P_{g}\right)$ is given by

$$
P_{g}=\frac{1}{2} V_{s}\left(i_{s_{\text {peak }}}\right)=\frac{D^{2} V_{s}}{4 L_{1} f_{s}} .
$$

2.2. Load and Bus Voltages. The load voltage $\left(V_{o}\right)$ for the driver can be obtained by equating the supply and load powers. The load power is given as $P_{o}=V_{o}^{2} / R$, where $R$ is the static resistance of the LED, given by

$$
R=\frac{V_{\mathrm{LED}}}{I_{\mathrm{LED}}}=\frac{V_{\gamma}+R_{\gamma} I_{\mathrm{LED}}}{I_{\mathrm{LED}}}=\frac{V_{\gamma}}{I_{\mathrm{LED}}}+R_{\gamma},
$$

in which $R \gamma$ and $V \gamma$ are the resistance and voltage of the LED, respectively. By assuming $100 \%$ efficiency, $V_{o}=D V_{s} / 2$ $\sqrt{k}$ and $k=L_{1} f_{s} / R$. The bus voltage can be calculated from the voltage ratio as follows:

$$
V_{B}=\frac{1-D}{D} V_{o}=\frac{(1-D) V_{g}}{2 \sqrt{K}} .
$$

To ensure a high PF, the converter must be operated in discontinuous conduction mode (DCM) and the critical limit for the duty cycle $\left(D_{l m}\right)$ can be obtained from the voltage transformation via $D_{l m}=\left(1+V_{s} / V_{B}\right)^{-1}$.

2.3. Reactive Components. The value of $L_{1}$ can be obtained from $L_{1}=D^{2} V_{s}^{2} /\left(4 P_{o} f_{s}\right)$ by assuming there are no losses. The bus capacitance for a known peak-to-peak voltage ripple is

$$
C_{1}=\frac{D^{2}}{8 V_{B} \pi L_{1} f_{s} f_{L} \Delta V_{B_{L F}}} V_{s}^{2} .
$$




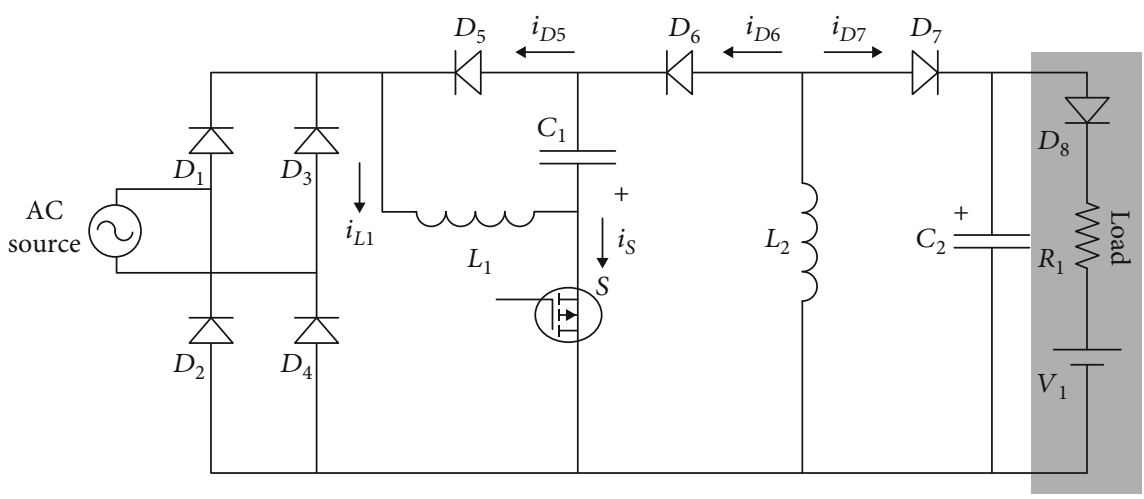

FIGURE 2: Circuit diagram of the integrated nonisolated LED driver.

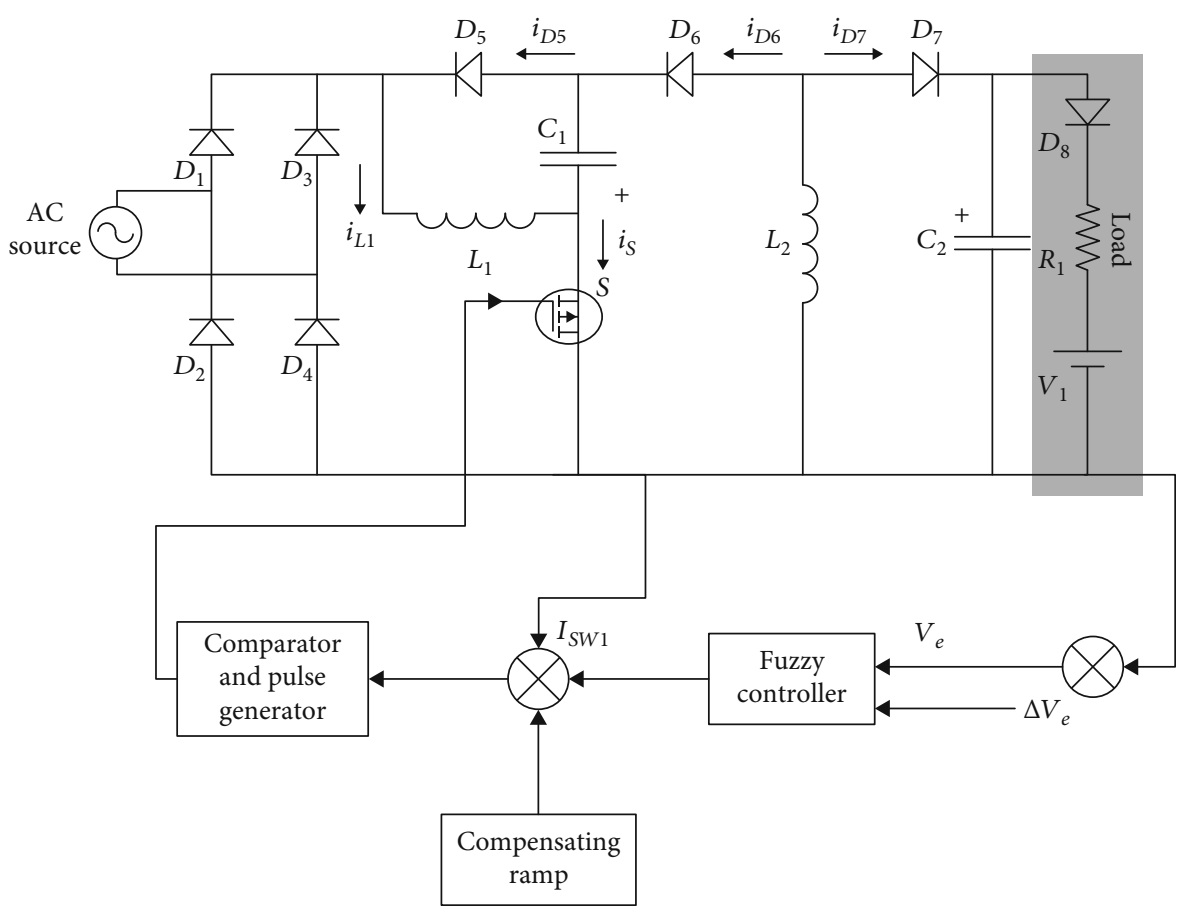

(a)

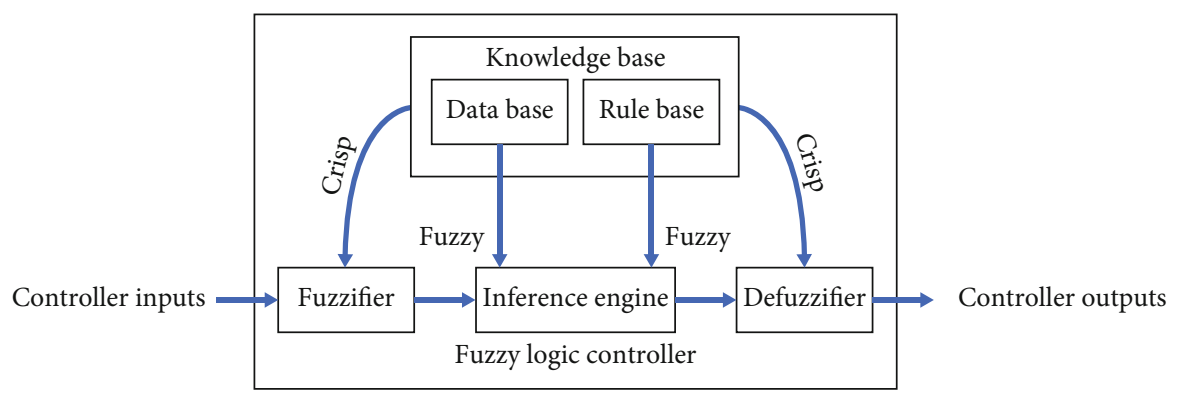

(b)

FIGURE 3: (a) Block diagram of the FPCC LED driver with compensating ramp; (b) FPCC components. 


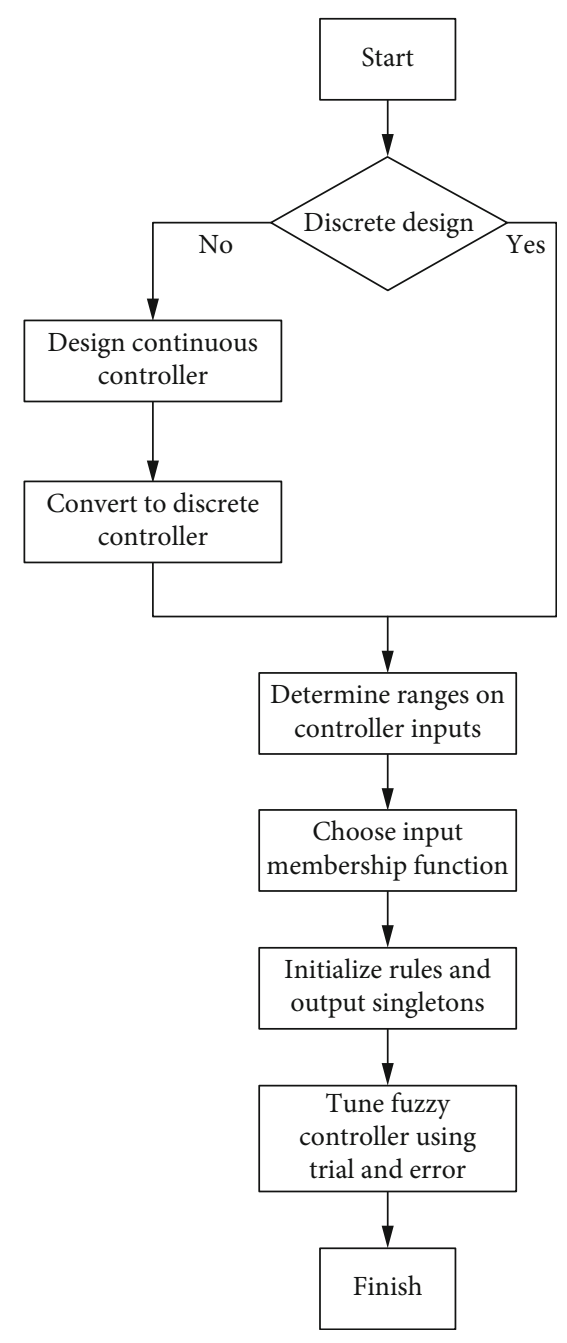

Figure 4: Process flow chart. from

The inductance and capacitance $L_{2}$ and $C_{2}$ are obtained

$$
\begin{gathered}
L_{2}=\frac{D V_{B}}{0.5 \Delta I_{\mathrm{LOHF}} f_{s}}, \\
C_{2}=\frac{D V_{O}}{\Delta V_{O_{\mathrm{HF}} f_{s}}},
\end{gathered}
$$

where $\Delta I_{\mathrm{LOHF}}$ is the current ripple and $\Delta V_{\mathrm{O}_{\mathrm{HF}}}$ is the output voltage ripple.

\section{Proposed Fuzzy Controlled LED Driver}

The driver is nonlinear and time varying from a control system point of view:

(1) The driver circuit possesses nonlinear characteristics owing to the voltage and power of the LEDs. At a nominal working voltage, the characteristics experience a large gradient. This means that a small change in voltage can lead to a significant change of current and therefore to a considerable change in the emitted
TABLE 1: Rule base.

\begin{tabular}{lccccccc}
\hline E & NB & NM & NS & ZE & PS & PM & PB \\
\hline NB & NB & NB & NB & NB & NM & NS & ZE \\
NM & NB & NB & NB & NM & NS & ZE & PS \\
NS & NB & NB & NM & NS & ZE & PS & PM \\
ZE & NB & NM & NS & ZE & PS & PM & PB \\
PS & NM & NS & ZE & PS & PM & PB & PB \\
PM & NS & ZE & PS & PM & PB & PB & PB \\
PB & ZE & PS & PM & PB & PB & PB & PB \\
\hline
\end{tabular}

TABLE 2: Design parameters.

\begin{tabular}{lc}
\hline Component & Value \\
\hline${\text { Switching frequency }\left(f_{\mathrm{s}}\right)}$ & $50 \mathrm{kHz}$ \\
Inductance $_{1}\left(L_{1}\right)$ & $2.5 \mathrm{mH}$ \\
Capacitance $_{1}\left(C_{1}\right)$ & $80 \mu \mathrm{F}$ \\
Inductance $_{2}\left(L_{2}\right)$ & $9 \mathrm{mH}$ \\
Capacitance $_{2}\left(C_{2}\right)$ & $40 \mu \mathrm{F}$ \\
Load resistance $(R)^{\text {Equivalent voltage of LED load }(V \gamma)}$ & $570 \Omega$ \\
\end{tabular}

light. Moreover, when devices are connected to nonlinear loads, there could be several nonlinear relations between the system variables

(2) The system is time varying because the parameters of the system change with the temperature and magnetic saturation

A fuzzy approach offers the possibility to model a nonlinear system using knowledge of many non-well-defined relations among the variables of the system and allows for the design of a controller that adapts itself to several working conditions. Thus, fuzzy logic seems a suitable solution both to model and to control drives. The circuit diagram of the driver with a compensation ramp is shown in Figure 3(a). The driver is controlled with a fuzzy voltage loop by a Mamdani type fuzzy inference system, and the outer current loop consists of a peak current control with slope compensation.

The error between the reference voltage and converter output voltage and its variation are the inputs to the FLC (see Equations (7) and (8)). The FPCC and its components are shown in Figure 3(b). The output voltage is tracked and compared to the reference signal, and the generated error $V_{\mathrm{e}}$ and change in error $V_{\mathrm{ce}}$ are given as inputs to the FLC to obtain a suitable signal to the current controller loop. In the current controller loop, three signals are used in order to generate the pulses to the switches: the inductor signal, the FLC signal, and the compensating ramp signal. Although not considered here, parameter and model uncertainties can be incorporated directly as fuzzy numbers in the fuzzy set theory.

The FLC consists of the following components: a fuzzifier converts crisp data into fuzzy data; a knowledge base contains a data base and a fuzzy rule set; an inference engine 


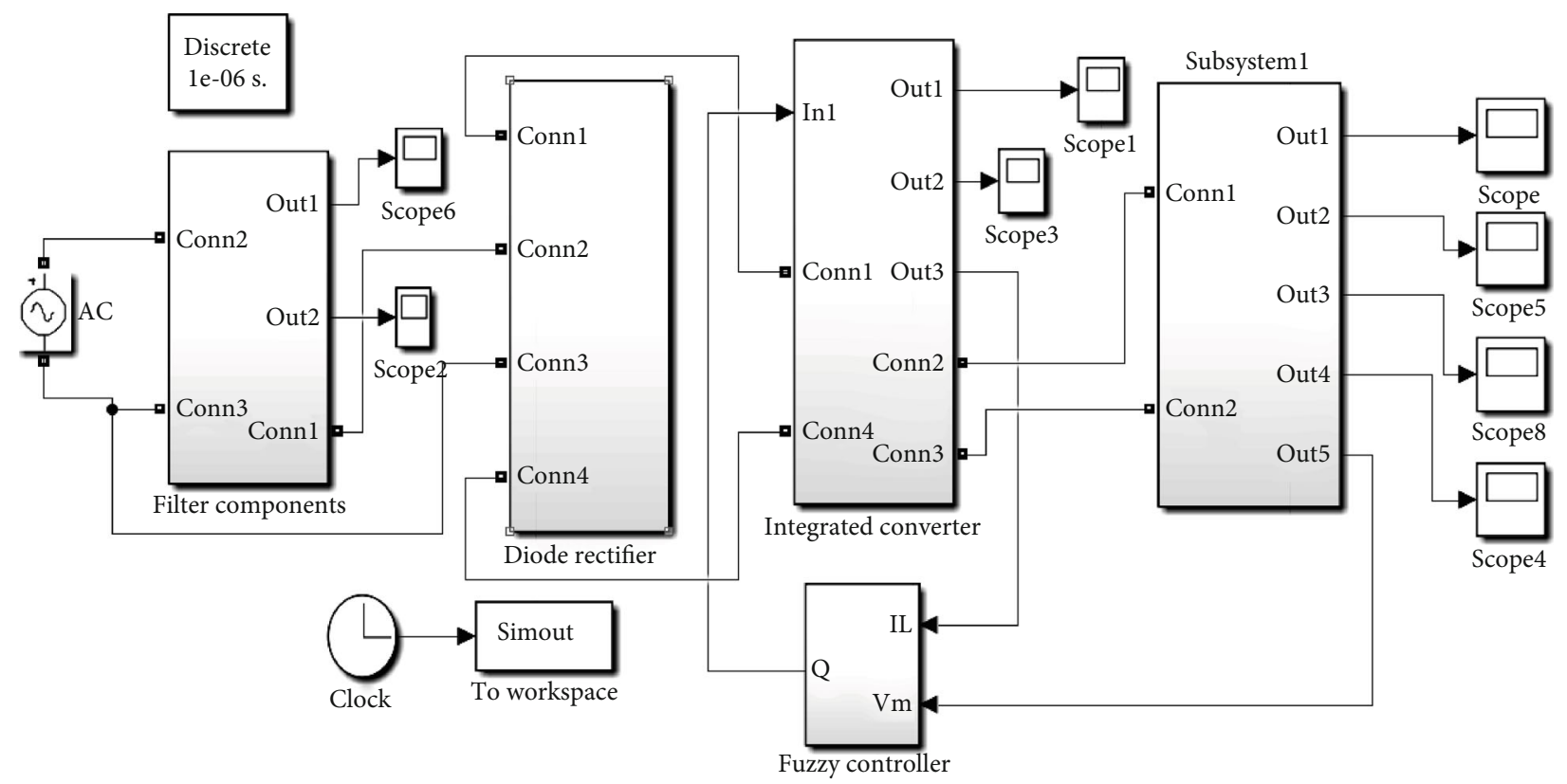

FIGURE 5: The Simulink model of the proposed FPCC integrated nonisolated LED driver.
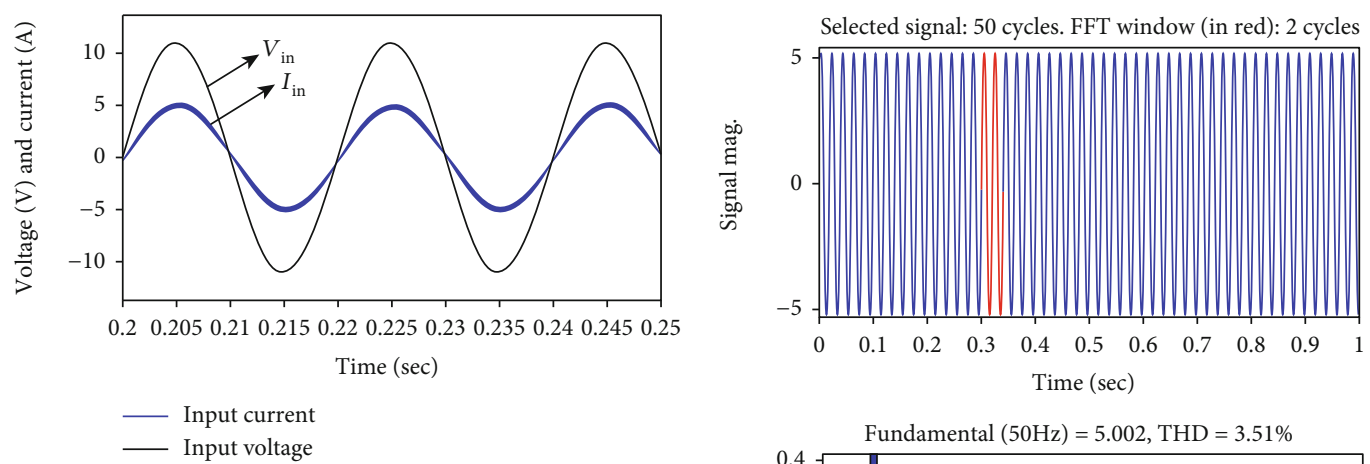

- Input voltage

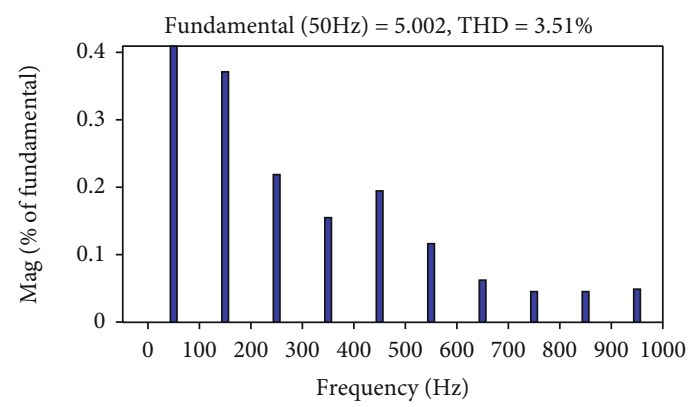

(a)

(b)

FIGURE 6: (a) Simulation results of input voltage and current; (b) current harmonic spectra. 


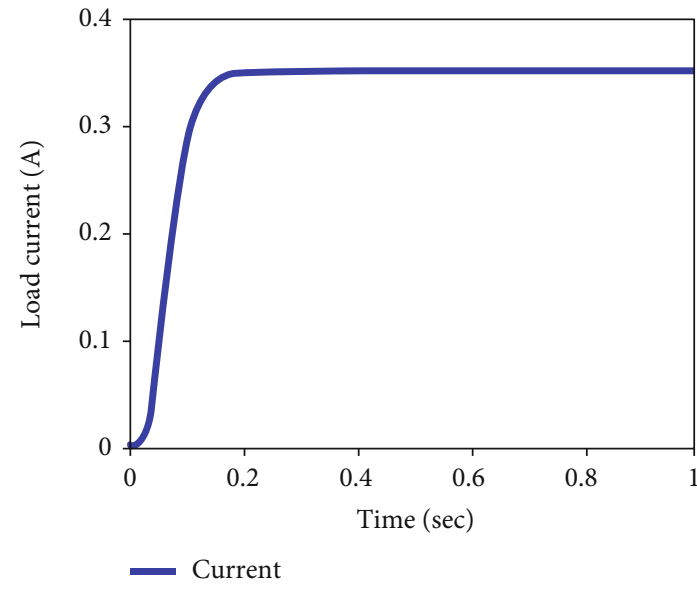

(a)

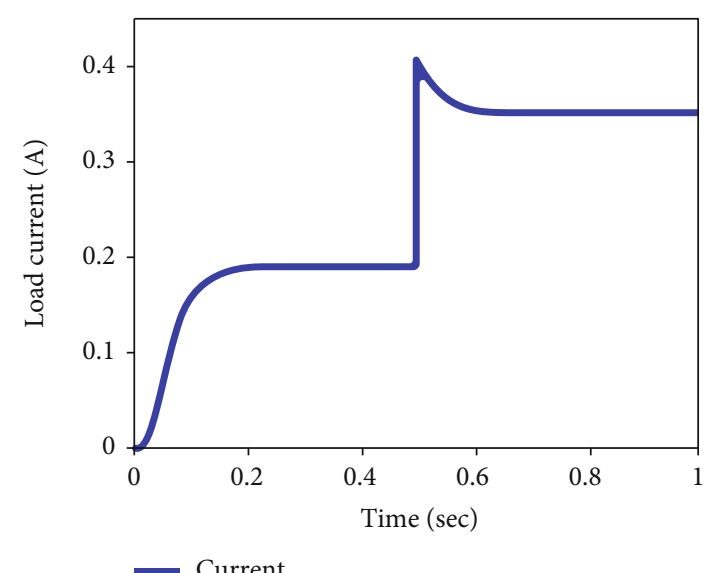

(b)

Figure 7: (a) Load current; (b) load current with dynamic change at $0.5 \mathrm{sec}$.

deduces the fuzzy control action from the knowledge base and simulates a human decision process; defuzzification yields a crisp value from the fuzzy action.

The FPCC, with the help of the knowledge and experience of an expert, improves the performance of the system. Applying intelligent control techniques for issues identified with uncertainty makes use of IF-THEN rules to define the relation between the inputs and the outputs. Simulation is carried out to check the performance of the design, and if the design is not considered satisfactory, modifications are made to tune the limits of the controller by changing the fuzzy rules and the procedure is repeated for better outcomes.

Several steps are involved in the design of fuzzy controllers as shown in Figure 4: (i) choosing the fuzzy controller inputs and outputs; (ii) choosing the preprocessing that is needed for the controller inputs, and possibly postprocessing that is needed for the outputs; and (iii) design of the four components of the fuzzy controller: the fuzzifier, the rule base, decision maker and defuzzifier.

3.1. Identification of Inputs and Outputs. The inputs of the FC are the error $V_{\mathrm{e}}$ and the variation of error $V_{\mathrm{ce}}$, which are derived from

$$
\begin{gathered}
V_{\mathrm{e}}=V_{0}-V_{\text {ref }}, \\
V_{\text {ce }}=V_{\mathrm{e}}(\mathrm{k})-V_{\mathrm{e}}(\mathrm{k}-1),
\end{gathered}
$$

where $V_{0}$ is the extant load voltage, $V_{\text {ref }}$ is the reference load, $V_{\mathrm{e}}$ is the voltage error, and subscript " $k$ " denotes the value taken at the opening of the $k^{\text {th }}$ switching cycle. The output of the FC is the duty ratio.

3.2. Fuzzifying the Inputs and Outputs. The world of the dissertation of the inputs is separated into 7 fuzzy sets of triangular shape. Outputs are also mapped into several fuzzy regions of numerous singletons.

3.3. Development of the Rule Base and Inference. The proposed system, having $7 * 7$ rules, is shown in Table 1 . It has seven variables, named NB, NM, NS, Z, PB, PM, and PS. Tri-
TABLE 3: Evaluation of \%THD and PF with different source voltage.

\begin{tabular}{lcc}
\hline Source voltage & Current THD $(\%)$ & Power factor \\
\hline 90 & 10.82 & 0.962 \\
120 & 8.81 & 0.971 \\
150 & 6.73 & 0.978 \\
230 & 3.51 & 0.987 \\
\hline
\end{tabular}

TABLE 4: Evaluated values of power factor and \%THD with different loads at rated voltage.

\begin{tabular}{lcc}
\hline Load $(\mathrm{W})$ & Current THD (\%) & Power factor \\
\hline $20 \mathrm{~W}$ & 5.74 & 0.949 \\
$35 \mathrm{~W}$ & 4.63 & 0.965 \\
$70 \mathrm{~W}$ & 3.51 & 0.987 \\
\hline
\end{tabular}

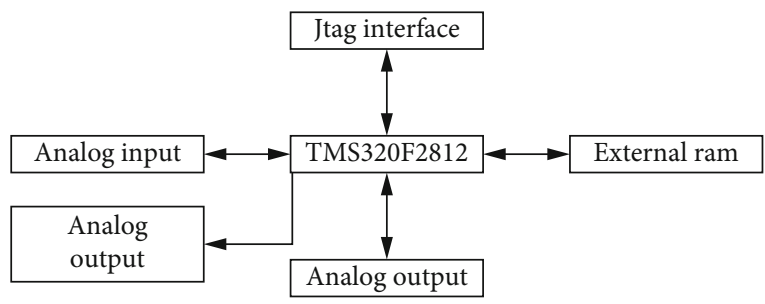

FIgURE 8: Hardware structure.

TABle 5: Experimental component details.

\begin{tabular}{lc}
\hline Component name & Series number \\
\hline Control switch (power IGBT) (SW1) & FGA15N120ANTD \\
Power diode $\left(D_{1}, D_{2}\right.$, and $\left.D_{3}\right)$ & MUR3040PT \\
DSP processor & TMS320F2812 \\
\hline
\end{tabular}

angular shapes are used as membership functions, and the center of gravity method is used for the defuzzification process. 


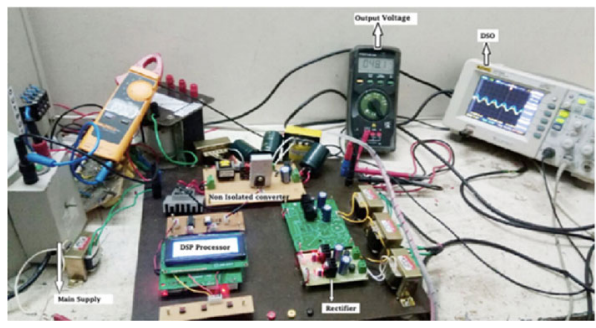

(a)

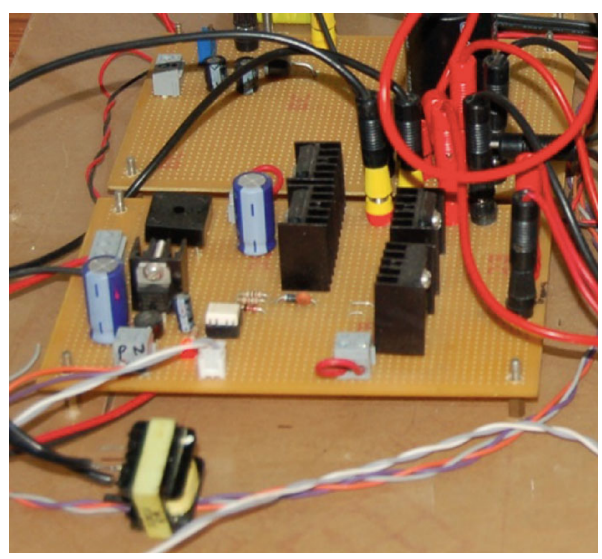

(b)

FIgURE 9: (a) Laboratory hardware; (b) converter close up.

\section{Design Parameters}

The driver circuit was built in the laboratory and tested with a universal input $(90 \mathrm{~V}-230 \mathrm{~V})$ range. The driver was designed to provide a power of $70 \mathrm{~W}$, with a rated lamp current of $350 \mathrm{~mA}$. The remaining component values are shown in Table 2.

\section{Results and Discussion}

5.1. Simulation Results. The proposed fuzzy peak current controlled integrated nonisolated LED driver was developed in the MATLAB/Simulink software package. Figure 5 shows the simulation model, in which a diode rectifier converts the AC source into DC, which is fed to the integrated converter. The output of the integrated converter is fed to the LED panel.

In order to control the driver unit, a proposed control is presented in a feedback loop. Figure 6(a) shows the simulation results of the input voltage of a current waveform rated at a voltage of $230 \mathrm{~V}$ and at full load $(70 \mathrm{~W})$. In the simulation, the waveform voltage magnitude is scaled to $10 \mathrm{~V}$ by multiplying with the factor 0.0307 . This result shows that the input current is in-phase with voltage and current waveform following a sinusoidal shape. The respective current harmonic spectrum is also shown in Figure 6(b), which demonstrates that the harmonic content presented in the current wave is below the international specifications (IEC-61000-32 ). The PF and percentage THD at this load are found to be 0.987 and $3.51 \%$, respectively. Figure $7(\mathrm{a})$ is the output current of the driver, which is maintained at $350 \mathrm{~mA}$. To evaluate the dynamic performance of the controller, a change of load was made at $0.5 \mathrm{sec}$ as shown in Figure 7(b), with a stepwise change in load from $175 \mathrm{~mA}$ to $350 \mathrm{~mA}$ (at $0.5 \mathrm{sec}$ ). An improved dynamic response is observed.

From Table 3, the performance of the converter is significantly improved with the universal input (90-230 V). The THD improves from $10.82 \%$ to $3.51 \%$. The PF of the driver in the entire range is found to be above 0.96 .
It is observed from Table 4 that the power factor is higher at full load conditions and the corresponding THD is lower $(0.987$ and $3.51 \%$ at $70 \mathrm{~W})$.

5.2. Experimental Results. An experimental setup was implemented to validate the simulation results. Microcontrollers based on FLCs for power converters were implemented, but due to the high sampling frequency, control DSPs were instead used. The proposed controller was implemented using a TMS320F2812 DSP, which is a 32-bit processor operating at $150 \mathrm{MHz}$. The digital converter contains the recompense network, fault amp, slant recompense, and PWM generator, which work in a discrete time domain. In this paper, we used a Texas Instruments TMS320F2812 DSP processor. The duty is to initially set to $100 \%$ but tripped using the cycle-by-cycle trip feature of the processor. The yield voltage of the converter is connected to a resistive "inspecting divider" arranged such that it is associated with DAC. The voltage is tested and changed over to advanced esteem. A digital reference (REF) is subtracted from the digital value, and the error value is used as an input to the digital controller. This represents the error amplifier and compensation network of the analog equivalent. The yield of the controller is increased by an additional term $K$, which scales the yield of the controller to computerized esteem well-suited for use with the D/A Converter (DAC). The general hardware structure is shown in Figure 8. The output of the converter is sampled by an A/D converter, which gives the digital value to the fuzzy controller. The controller processes the data to produce a PWM signal to the control switch SW1 of the converter.

The line voltage and current waveforms, load current and voltage waveforms, and current harmonic content were observed. The experimental component details are listed in Table 5. Figure 9(a) shows the experimental setup of the proposed FPCC integrated nonisolated LED driver with a controller, while Figure 9(b) is a detailed picture of the controller.

The supply current was in-phase with a supply voltage of $230 \mathrm{~V}$ ( $V_{\text {in }}: 300 \mathrm{~V} /$ div; $I_{\text {in }}: 0.5 \mathrm{~A} /$ div $)$. The corresponding measured $\mathrm{PF}$ is 0.973 , and \% $\mathrm{THD}$ is $5.67 \%$. The respective harmonic spectra are shown in the left of Figure 10(a), while 


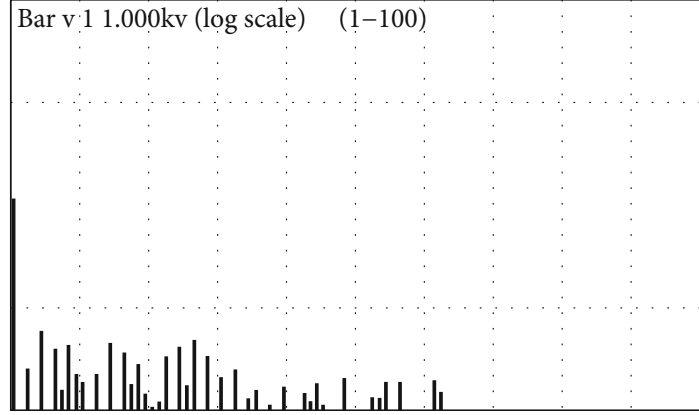

(a)

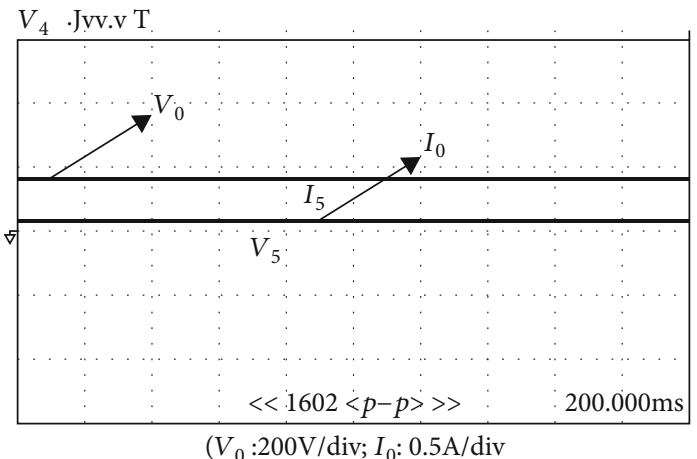

(b)

FIGURE 10: (a) Line current harmonic spectrum; (b) load voltage (V) and load current (A).

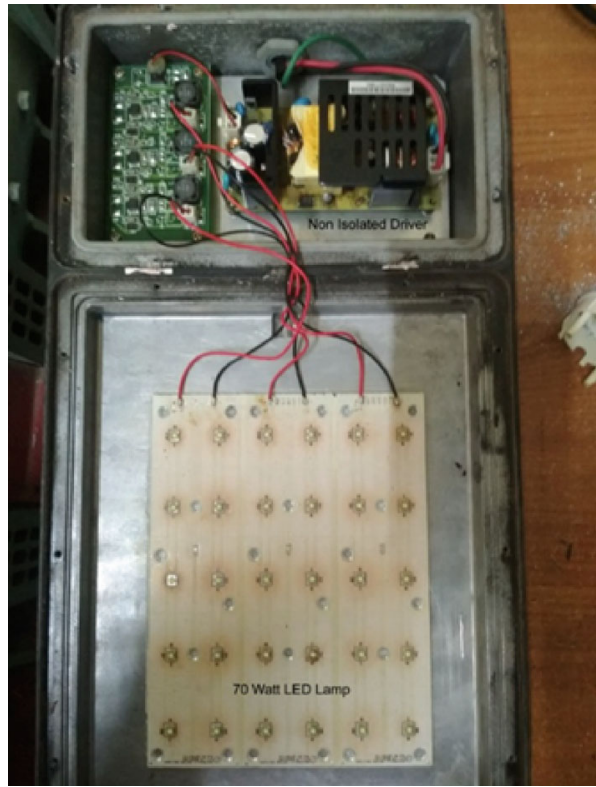

(a)

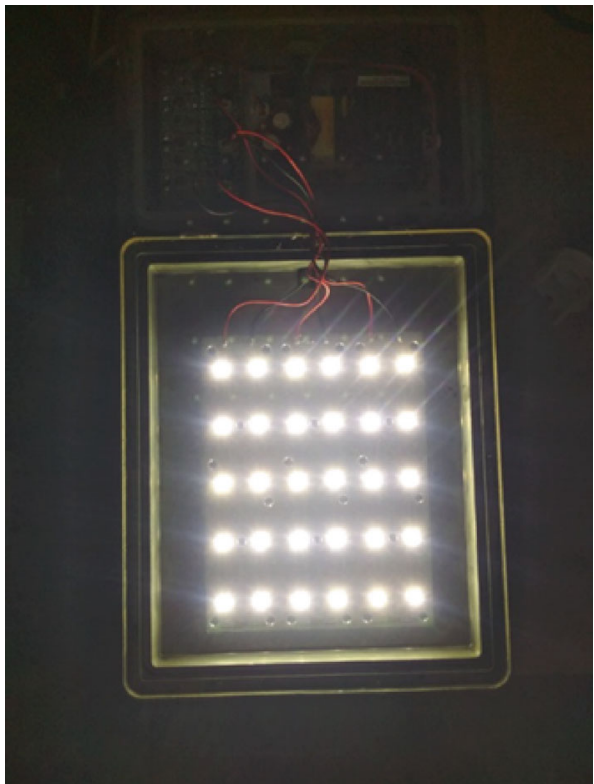

(b)

FiguRE 11: (a) LED driver with panel; (b) system under operation.

the load current and load voltage are shown in Figure 10(b). The experimental setup of the driver with an LED lamp (component values as in Table 2) and the lamp under working conditions are shown in Figures 11(a) and 11(b), respectively.

A comparison of the simulation and experimental results is provided in Table 6, from which it can be concluded that the proposed DSP-based FPCC integrated nonisolated LED driver operating at a low voltage $(90 \mathrm{~V})$ gives a low $\mathrm{PF}$ and high \%THD with respect to the current. The PF increases to 0.987 in the simulations and 0.973 in the experiments at the high voltage $(230 \mathrm{~V})$, and the corresponding THD is $3.51 \%$ in the simulations and $5.5 \%$ in the experiments at a full load of $70 \mathrm{~W}$. From the experimental and simulation results, it is clear that the proposed FPCC integrated isolated LED driver implemented through DSP is suitable for low, medium, and high voltage operation.
TABLE 6: Simulation and experimental results at different source voltages at full load.

\begin{tabular}{lccccc}
\hline \multicolumn{3}{c}{ Simulation results } & \multicolumn{3}{c}{ Experimental results } \\
Voltage & THD (\%) & PF & Voltage & THD (\%) & PF \\
\hline 90 & 10.82 & 0.962 & 90 & 13.2 & 0.94 \\
120 & 8.81 & 0.971 & 110 & 12.4 & 0.956 \\
150 & 6.73 & 0.978 & 150 & 10.71 & 0.961 \\
230 & 3.51 & 0.987 & 230 & 5.67 & 0.973 \\
\hline
\end{tabular}

Table 7 shows a comparison of the existing topologies with the proposed topology. The power factor is 0.987 , close to unity, and the THD is $3.51 \%$, relatively low compared to existing topologies. Furthermore, Table 8 shows a comparison of existing controllers with the proposed controller. It is observed that the proposed controller exhibits better performance. 
TABLE 7: Comparisons between the existing single-stage LED drivers and the proposed driver.

\begin{tabular}{lcc}
\hline \multirow{2}{*}{ LED driver } & \multicolumn{2}{c}{ Specification parameter } \\
& Power factor (PF) & Total harmonic distortion (\%THD) \\
\hline Integrated buck-flyback converter [18] & 0.970 & $27.5 \%$ \\
Single-stage LED driver [10] & 0.99 & $7.9 \%$ \\
Single-stage LED streetlight driver with soft-switching and interleaved PFC [12] & 0.97 & $5 \%$ \\
Proposed & 0.987 & $3.51 \%$ \\
\hline
\end{tabular}

TABLE 8: Comparisons of existing controllers and the proposed controller.

\begin{tabular}{lcc}
\hline Controllers & Power factor (PF) & $\begin{array}{c}\text { Specification parameter } \\
\text { Total harmonic distortion (\%THD) }\end{array}$ \\
\hline Fixed-frequency constant-current control [18] & 0.970 & $27.5 \%$ \\
QR valley-switching scheme [21] & 0.93 & $23 \%$ \\
Conventional current control [15] & 0.96 & $28 \%$ \\
Proposed & 0.987 & 3.51 \\
\hline
\end{tabular}

\section{Conclusions}

This paper presents a fuzzy integrated nonisolated LED driver designed to achieve a high-power factor (PF). It consists of fuzzy control in a voltage loop and peak current control in a current loop. The voltage loop regulates the output voltage, and the current loop improves the power factor. Fuzzy logic is used in a feedback path and linear programming rule to govern the magnitude of the reference current during this proposed technique in order to regulate the switch's duty cycle for shaping the input current. The proposed method avoids complexity related to nonlinearity of switching converters and is ready to react quickly to load changes, so controller processing leads to better dynamic performance. The experimental results at steady state showed that the proposed control strategy is capable of producing a power factor value of almost unity under a wide range of supply voltage and load power conditions. The experimental results show that the $\mathrm{PF}$ of the driver is 0.973 and the \% THD is $5.67 \%$ at full load, and therefore, the efficiency of the driver is $86.5 \%$, which meets international regulations (IEC-61000-3-2).

\section{Abbreviations}

PF: $\quad$ Power factor

LED: Light-emitting diode

FLC: Fuzzy logic controller

DSP: Digital signal processor

FPCC: Fuzzy peak current controlled

THD: Total harmonic distortion.

\section{Data Availability}

Data is available upon request.

\section{Conflicts of Interest}

The authors declare that they have no conflicts of interest.

\section{Acknowledgments}

This project was partially supported by the National Key Research and Development Program of China (Grant No. 2017YFB0701700). This work was supported by the National University Malaysia Pahang (UMP) (Grant No. PGRS200321), and Mr. A.S. Veerendra is working as a research scholar under UMP's Doctoral Research Scheme (DRS).

\section{References}

[1] Y. Wang, J. Alonso, and X. Ruan, "A review of LED drivers and related technologies," IEEE Transactions on Industrial Electronics, vol. 64, no. 7, pp. 5754-5765, 2017.

[2] W.-j. Cha, Y.-W. Cho, and J.-M. Kwon, "Single powerconversion LED backlight driving system with high power factor control," Journal of Display Technology, vol. 10, no. 5, pp. 407-413, 2014.

[3] T.-P. Sun and C.-H. Wang, "Specially designed driver circuits to stabilize LED light output without a photodetector," IEEE Transactions on Power Electronics, vol. 27, no. 9, pp. 41404152, 2012.

[4] Y. Wang, Y. Guan, D. Xu, and W. Wang, "A CLCL resonant DC/DC converter for two-stage LED driver system," IEEE Transactions on Industrial Electronics, vol. 63, pp. 28832891, 2015.

[5] P. Athalye, M. Harris, and G. Negley, "A two-stage LED driver for high-performance high-voltage LED fixtures," in 2012 Twenty-Seventh Annual IEEE Applied Power Electronics Conference and Exposition (APEC), pp. 2385-2391, Orlando, FL, USA, February 2012.

[6] X. Xie, M. Ye, Y. Cai, and J. Wu, "An opto coupler less twostage high power factor LED driver," in 2011 Twenty-Sixth Annual IEEE Applied Power Electronics Conference and Exposition (APEC), pp. 2078-2083, Fort Worth, TX, USA, March 2011.

[7] W. Lin, H. Chen, and S. Ke, "Research on a single-stage flyback/boost LED driver with lower output ripple," in 2016 IEEE 2nd Annual Southern Power Electronics Conference (SPEC), pp. 1-5, Auckland, New Zealand, December 2016. 
[8] Y. Guo, S. Li, A. T. L. Lee, S.-C. Tan, C. K. Lee, and S. Y. R. Hui, "Single-stage AC/DC single-inductor multiple-output LED drivers," IEEE Transactions on Power Electronics, vol. 31, pp. 5837-5850, 2015.

[9] J. W. Fan, J. P.-W. Chow, W.-T. Chan et al., "Modeling and experimental assessment of the EMI characteristics of switching converters with power semiconductor filters," IEEE Transactions on Power Electronics, vol. 35, no. 3, pp. 2519-2533, 2020.

[10] S. Mangkalajan, C. Ekkaravarodome, K. Jirasereeamornkul, P. Thounthong, K. Higuchi, and M. K. Kazimierczuk, "A single-stage LED driver based on ZCDS class-E currentdriven rectifier as a PFC for street-lighting applications," IEEE Transactions on Power Electronics, vol. 33, no. 10, pp. 87108727, 2018.

[11] Y. Wang, X. Deng, Y. Wang, and D. Xu, "Single-Stage bridgeless LED driver based on a CLCL resonant converter," IEEE Transactions on Industry Applications, vol. 54, no. 2, pp. 1832-1841, 2018.

[12] C.-A. Cheng, C.-H. Chang, H.-L. Cheng, E.-C. Chang, T.Y. Chung, and M.-T. Chang, "A single-stage LED streetlight driver with soft-switching and interleaved PFC features," Electronics, vol. 8, no. 8, p. 911, 2019.

[13] G. G. Pereira, M. A. Dalla Costa, J. M. Alonso, M. F. de Melo, and C. H. Barriquello, "LED driver based on input current shaper without electrolytic capacitor," IEEE Transactions on Industrial Electronics, vol. 64, no. 6, pp. 4520-4529, 2017.

[14] J. M. Alonso, D. Gacio, A. J. Calleja et al., "Reducing storage capacitance in off-line LED power supplies by using integrated converters," in 2012 IEEE Industry Applications Society Annual Meeting, pp. 1-8, Las Vegas, NV, USA, October 2012.

[15] J. Alonso, J. Vina, D. Gacio, G. Martinez, and R. O. Sanchez, "Analysis and design of the integrated double buck-boost converter as a high-power-factor driver for power-LED lamps," IEEE Transactions on Industrial Electronics, vol. 59, no. 4, pp. 1689-1697, 2012.

[16] G. M. Soares, P. S. Almeida, J. M. Alonso, and H. A. C. Braga, "Capacitance minimization in offline LED drivers using an active-ripple-compensation technique," IEEE Transactions on Power Electronics, vol. 32, no. 4, pp. 3022-3033, 2017.

[17] D. Gacio, J. M. Alonso, J. Garcia, D. Garcia-Llera, and J. Cardesin, "Optimization of a front-end DCM buck PFP for an HPF integrated single-stage LED driver," IEEE Journal of Emerging and Selected Topics in Power Electronics, vol. 3, no. 3, pp. 666-678, 2015.

[18] D. Gacio, J. M. Alonso, A. J. Calleja, J. Garcia, and M. RicoSecades, "A universal-input single-stage high-power-factor power supply for HB-LEDs based on integrated buck-flyback converter," IEEE Transactions on Industrial Electronics, vol. 58, no. 2, pp. 589-599, 2011.

[19] T. Qian and W. Wu, "Analysis of the ramp compensation approaches to improve stability for buck converters with constant on-time control," IET Power Electronics, vol. 5, no. 2, pp. 196-204, 2012.

[20] M. Subbarao, C. S. Babu, and S. Satyanarayana, "Design and analysis of variable switching frequency controlled integrated switched mode power converter for class C \& class D appliances," Ain Shams Engineering Journal, vol. 9, no. 4, pp. 2849-2858, 2018.

[21] Y.-C. Li, "A novel control scheme of quasi-resonant valleyswitching for high-power-factor AC-to-DC LED drivers,"
IEEE Transactions on Industrial Electronics, vol. 62, no. 8 , pp. 4787-4794, 2015.

[22] S. Sagiroglu, I. Colak, and R. Bayindir, "Power factor correction technique based on artificial neural networks," Energy Conversion and Management, vol. 47, no. 18-19, pp. 32043215, 2006.

[23] C. S. Chiu, C. T. Shen, and G. C. Hsieh, "Universal lighting control of unknown connected light emitting diode arrays via a T-S fuzzy model-based approach," IET Power Electronics, vol. 8, no. 2, pp. 151-164, 2015.

[24] T.-F. Wu, C.-H. Chang, and Y.-H. Chen, "A fuzzy-logiccontrolled single stage converter for PV-powered lighting system applications," IEEE Transactions on Industrial Electronics, vol. 47, no. 2, pp. 287-296, 2000.

[25] M. He and J. Xu, "Nonlinear PID in digital controlled buck converters," in APEC 07 - Twenty-Second Annual IEEE Applied Power Electronics Conference and Exposition, pp. 1461-1465, Anaheim, CA, USA, March 2007.

[26] C. Buccella, C. Cecati, and H. Latafat, "Digital control of power converters - a survey," IEEE Transactions on Industrial Informatics, vol. 8, no. 3, pp. 437-447, 2012.

[27] C. A. Sepúlveda, J. A. Muñoz, J. R. Espinoza, M. E. Figueroa, and C. R. Baier, "FPGA v/s DSP performance comparison for a VSC-based STATCOM control application," IEEE Transactions on Industrial Informatics, vol. 9, no. 3, pp. 1351-1360, 2013.

[28] K.-H. Tseng and C.-L. Chen, "Design and hardware implementation for a full-bridge phase-shift PWM DC/DC converter system with FPGA-based PI gain-scheduling control," in 2011 6th IEEE Conference on Industrial Electronics and Applications, pp. 1578-1582, Beijing, China, June 2011.

[29] L. Guo, J. Y. Hung, and R. M. Nelms, "Evaluation of DSPbased PID and fuzzy controllers for DC-DC converters," IEEE Transactions on Industrial Electronics, vol. 56, pp. 2237-2248, 2009.

[30] M. SubbaRao, C. S. Babu, S. Satyanarayana, and P. C. B. Naidu, "Digital fuzzy current mode controlled integrated PFC converter with external ramp compensation," Journal of Circuits, Systems, and Computers, vol. 27, no. 9, article 1850147, 2018. 